\title{
A ÉTICA DOS FINS E DOS MEIOS ANALISADA A PARTIR DA IDEIA DE JUSTIÇA FISCAL
}

\section{THE ETHICS OF PURPOSES AND MEANS ANALYZED FROM THE VIEW OF FISCAL JUSTICE}

Bruno Bastos de Oliveira ${ }^{1}$

\section{RESUMO}

A partir da ideia de tributação é possível considerar a necessidade de efetivação de igualdades e liberdades fundamentais dos contribuintes, assumindo o Estado papel fundamental no âmbito sócio-político. Utilizando-se do método dedutivo, com técnica de pesquisa bibliográfica, objetiva-se analisar os fins e os meios do Direito Tributário, com vistas a atingir os fins buscados com a arrecadação tributária, levando-se em conta os direitos fundamentais dos contribuintes. Conclui-se que a efetivação de cidadania, das liberdades e da democracia, sob o prisma da arrecadação tributária, se mostra extremamente relevante, chegando-se assim a ideia de justiça tributária.

Palavras-chave: Tributação. Fins. Meios. Justiça. Justiça Fiscal.

\begin{abstract}
Based on the idea of taxation, it is possible to consider the need for the realization of the fundamental equality and freedoms of taxpayers, with the State assuming a fundamental role in the socio-political sphere. Using the deductive method, with bibliographic research technique, the objective is to analyze the ends and means of Tax Law, with a view to achieving the ends sought with the tax collection, taking into account the fundamental rights of taxpayers. It is concluded that the realization of citizenship, freedoms and democracy, from the perspective of tax collection, is extremely relevant, thus arriving at the idea of tax justice.
\end{abstract}

Keywords: Taxation. Purposes. Means. Justice. Tax Justice.

\footnotetext{
${ }^{1}$ Advogado e Professor. Consultor Jurídico, especialista na área fiscal. Pós-doutor em Direito pela UNIMAR Universidade de Marília - SP, sendo bolsista PNPD. Professor do Programa de Pós-graduação em Direito Mestrado e Doutorado - da UNIMAR - Universidade de Marília - SP. Doutor em Ciências Jurídicas - Direitos Humanos e Desenvolvimento - pela Universidade Federal da Paraíba. Mestre em Ciências Jurídicas, área de concentração Direito Econômico pela Universidade Federal da Paraíba. Especialista em Direito Tributário pela Universidade do Sul de Santa Catarina . Afiliação: Universidade de Marília - UNIMAR, São Paulo. ORCID: http://orcid.org/0000-0002-4563-6366. Lattes: http://lattes.cnpq.br/1416133820227723 E-mail: bbastos.adv@gmail.com
} 


\section{INTRODUÇÃO}

O objetivo do presente estudo é traçar os aspectos relevantes para a observação dos fins e dos meios do Direito Tributário, analisando o papel que a tributação vem assumindo no que concerne a efetivação de direitos e garantias previstos no âmbito da Constituição Federal vigente no Brasil, apontando para a questão da cidadania à luz da Ciência Política e do Direito Tributário, denominando-se assim de cidadania tributária, a partir da correta interpretação e análise do que pode ser entendido como justiça fiscal. Hodiernamente muito se fala em efetivação de cidadania, das liberdades e da democracia, porém necessário observar tais elementos sob o prisma da arrecadação tributária, fundamental para a própria manutenção do Estado.

A noção de tributação, como fenômeno de imposição estatal sobre o particular, unilateral e compulsória, passa obrigatoriamente pela verificação de como é implementado o direito de liberdade ao longo da história, sendo necessário que se tenha em mente que a expressão liberdade foi e ainda é objeto de estudo de notáveis pensadores, que se debruçaram sobre o tema quando da análise da conjuntura política e social vivida por cada Estado em determinadas épocas.

Parte-se de da noção de liberdade na antiguidade, com forte valorização do coletivo, passando pela visão liberal, típica de meados do século XIX, até a visão contemporânea, tal como a exposta pela Constituição Federal vigente. A forma como tal valor é concretizado está umbilicalmente relacionada com a relação jurídica travada entre Estado e contribuinte, onde o primeiro, utilizando-se do poder que lhe foi outorgado pela própria Constituição, impõe ao segundo o pagamento de tributos, limitando assim os direitos individuais em prol de benefício maior, qual seja o bem-estar coletivo. Desse contexto é possível questionar se os fins da tributação, e por conseguinte do Direito Tributário, estão sendo alcançados e por quais meios tais finalidades estão sendo buscadas.

Não se pode negar que a arrecadação tributária, como já mencionado, é fenômeno necessário à própria manutenção estatal, daí a decorrência lógica acerca da importância da questão fiscal, tanto politica quanto juridicamente. A partir do reconhecimento dessa importância os Estados têm delineado a forma como o sistema tributário nacional deve ser estruturado, apontando o complexo de tributos, bem como a forma como dá a arrecadação e a fiscalização dessas exações tributárias. 
É justamente a partir da análise de como o sistema tributário de determinado Estado se apresenta que, limitando-se o objeto de estudo ao sistema tributário brasileiro, se torna necessário a consecução de observação menos formal e mais profunda, buscando responder basicamente a duas questões: os fins e os meios do Direito Tributário e da tributação tornam o sistema tributário nacional justo? A partir desse sistema tributário posto, é possível se falar e concretização de cidadania tributária?

Responder tais questões não se revela tarefa das mais simples, porém, no presente estudo, utilizando-se do método dedutivo, com técnica de pesquisa bibliográfica, busca-se enfrenta-las a partir das concepções clássicas sobre teorias da justiça, cidadania e ética. A reflexão que aqui se propõe deve ensejar em base fundamental para um novo modelo de sistema tributário a partir de reforma pautada em elementos éticos, de modo a permitir que a justiça fiscal possa ser alcançada de maneira efetiva. O Estado tem o poder de tributar objetivando basicamente a obtenção de receitas, mas para atingir tal finalidade não é possível se valer de meios que fujam dos padrões éticos aceitáveis constitucionalmente, sob pena de viciar também o fim perseguido.

Assim, o presente artigo está estruturado em quatro seções fundamentais. A primeira tratando sobre o sentido genérico de justiça fiscal, partindo na segunda seção para uma análise sobre a questão da justiça para John Rawls, relacionando-se à justiça fiscal. Nas seções três e quatro analisa-se as questões do dever fundamental de pagamento de tributos, atrelado a ideia de solidariedade, bem como a possibilidade de concretização da cidadania fiscal.

\section{O SENTIDO GENÉRICO DE JUSTIÇA FISCAL A PARTIR DO SISTEMA TRIBUTÁRIO NACIONAL VIGENTE E A VISÃO DOS DIREITOS HUMANOS NO ÂMBITO DA RELAÇÃO JURÍDICA TRIBUTÁRIA.}

A partir da evolução da forma como se concebe o valor fundamental liberdade, é possível estabelecer diferenças no que tange ao posicionamento do cidadão contribuinte em relação ao Estado. Não se fala mais em relação de imposição onde se busca um único fim: a arrecadação. Pelo menos não é essa ideia que aqui se defende.

Nesse viés, a própria Constituição Federal de 1988, ao consagrar o valor liberdade e acrescer a ele vários outros específicos à ordem tributária, se coloca como verdadeiro escudo protetivo do cidadão nessa relação jurídica tributária, que é desigual por natureza. Assim, assentado está a intima relação entre liberdade, justiça fiscal e cidadania tributária. 
Feita essas breves considerações acerca da liberdade como valor fundamental, necessário enquadrá-la no âmbito dos direitos humanos, algo tão aclamado na contemporaneidade e que ainda gera debates infindáveis, especialmente quando analisado sob a ótica da relação jurídica tributária travada entre contribuinte e Estado.

Conforme afirma Michel Villey (2007, p. 02), "os direitos humanos são um produto da época moderna". A partir do referido autor, tem-se que uma das principais críticas que se faz aos direitos humanos é o fato de serem direitos retóricos, logo com grande dificuldade de aplicação prática.

Qualquer discussão sobre Direitos Humanos necessário considerar a existência de complexo jurídico para tutela de questões extremamente caras à humanidade, perpassando por direitos fundamentais como a vida, a liberdade, a intimidade, a propriedade, a segurança, a nacionalidade, a cidadania, o devido processo legal, dentre diversos outros.

Os Direitos Humanos foram evidenciados após as catastróficas consequências da segunda guerra mundial, cujo propósito transcendeu a conquista de mercados, territórios, poder ou riquezas, mas almejou precipuamente a sobreposição de uma raça em face das demais, ocasião em que importantes organismos e instrumentos jurídicos de proteção aos direitos humanos foram criados, com proeminência de sistemas globais e regionais.

Assim, a terminologia "Direitos Humanos" aduz a arcabouço normativo em torno do gênero humano com o fim de tutelar questões extremamente caras à humanidade e que, na esteira do que leciona Piovesan (2013, p. 181), estão "em constante processo de construção e reconstrução", dinâmica essa também apontada por Portela (2014, p. 183) ao afirmar que "a formação do rol de normas de direitos humanos confunde-se com a história da humanidade e é produto de várias origens, que podem ser localizadas em diferentes civilizações e que se apoiam nos mais variados fundamentos".

Ainda diante da imprecisão na terminologia "direitos humanos", a Declaração Universal dos Direitos Humanos, proclamada em 1948, instrumento de caráter não-vinculante, principiológico, propositivo e, por que não admitir, com saliente viés político, trouxe rol de relevantes direitos fundamentais, conquanto a esperada força vinculante e coercitiva só viessem a surgir em 1966, durante a guerra fria, ocasião em que foram celebrados dois tratados distintos, um deles sendo o Pacto dos Direitos Civis e Políticos, promovido pelos EUA e Europa Ocidental, e o outro o Pacto dos Direitos Econômicos, Sociais e Culturais, com maior afinidade aos anseios socialistas (PORTELA, 2014). 
André de Carvalho Ramos (2014, p. 27), após conceituar direitos humanos como conjunto de direitos essenciais e indispensáveis à vida digna, leciona que "não há um rol predeterminado desse conjunto mínimo de direitos essenciais a uma vida digna" e que "as necessidades humanas variam e, de acordo com o contexto histórico de uma época, novas demandas sociais são traduzidas juridicamente e inseridas na lista dos direitos humanos", demonstrando assim o longo e árduo processo histórico que delineou aquilo que atualmente se conhece por direitos humanos, cujos episódios históricos foram muitas vezes marcados por derramamento de sangue.

Ainda diante da imprecisão na terminologia "direitos humanos", a Declaração Universal dos Direitos Humanos, proclamada em 1948, instrumento de caráter não-vinculante, principiológico, propositivo e, por que não admitir, com saliente viés político, trouxe rol de relevantes direitos fundamentais, conquanto a esperada força vinculante e coercitiva só viessem a surgir em 1966, durante a guerra fria.

Identificam-se cinco dimensões dos direitos humanos, quais sejam: dimensão direitos civis e políticos (ou direitos de liberdade), dimensão dos direitos econômicos, sociais e culturais (ou direitos de igualdade), dimensão dos direitos de solidariedade (ou fraternidade ou cooperação internacional), além da existência de outras duas dimensões, sendo uma relacionada com os direitos advindos da globalização política (democracia, informação e pluralismo) e outra concernente ao direito à paz.

A tributação, mais do que um dever, um direito do Estado, deve ser realizada a partir de elementos mínimos necessários de respeito ao contribuinte, aos aclamados direitos humanos (ou fundamentais, em caso de positivação pelo direito interno) destes. Parece evidente que nesse aspecto a crítica feita por Villey é por demais cabível, vez que na prática se torna cada vez mais difícil observar a concretização desses direitos humanos dos contribuintes.

Muito se fala em justiça fiscal, até mesmo de forma peculiar ao aspecto desenvolvimentista do Estado, porém o que seria essa tão importante e utópica justiça? Responder essa pergunta é necessário para que seja possível a resposta àquela outra posta como objetivo do presente trabalho, qual seja: o sistema tributário nacional é justo?

Parte-se aqui de análise genérica sobre o sistema tributário nacional. É uníssono o entendimento de que a carga tributária suportada pelos contribuintes deve ser proporcional a riqueza dos mesmos, devendo assim, ocorrer prestígio à tributação direta (a incidente sobre o próprio contribuinte, ou seja, aquele que realiza o fato gerador do tributo), para que seja possível a superação gradativa da denominada injustiça fiscal. Como reflexo dessa injustiça, ocorre o 
fortalecimento das desigualdades sociais, tanto em âmbito interno como externo aos entes federados.

Portanto, o fomento da tão festejada e aqui ainda genérica justiça fiscal no ordenamento tributário brasileiro passa pela desconcentração da arrecadação dos tributos indiretos (aqueles em que ocorre o fenômeno da repercussão tributária, ou seja, quem arca com o ônus da tributação não é quem efetivamente realiza o fato gerador do tributo, tal como acontece, por exemplo, no ICMS - Imposto sobre a circulação de mercadorias e serviços, no qual a repercussão tributária recai sobre o consumidor final) e o efetivo exercício da progressividade, como técnica de concretização do princípio constitucional da capacidade contributiva e se revelando um dos caminhos mais largos e propensos à efetivação desse ideal.

Aspecto importante também se à clara insegurança jurídica vivenciada, ante a grande pulverização normativa em matéria tributária. De outra banda, a Constituição Federal de 1988 revolucionou com relação às garantias fundamentais, uma vez que o rol de direitos já vinha sendo desenvolvido no decorrer das Constituições anteriores.

Possível identificar a estruturação do sistema tributário a partir de um caráter preponderantemente valorativo, com ênfase nos denominados princípios constitucionais, havendo a fixação de claros limites constitucionais ao poder de Estado, fundamentais para a ampliação do sistema de proteção aos contribuintes na relação jurídica tributária.

O poder de tributar "é decorrência inevitável da soberania que o Estado exerce sobre as pessoas de seu território, ao qual corresponde, por parte dos indivíduos, um dever de prestação" (NOGUEIRA, 1973, p.140). É possível entender que o poder de tributar é "poderdireito" e não "poder-força", uma vez que, os próprios integrantes da sociedade organizada reconhecem ao Estado o monopólio da violência física legítima de forma bem sucedida, tal como ensina o professor Paulo Bonavides (2006, p.70), com o objetivo que esse proteja e supra de forma efetiva o bem comum social, cumprindo assim a soberania estatal.

O texto constitucional positivado regulou a relação jurídica entre contribuinte e Estado, ou ainda, governante e governado no momento em que inseriu em sua substância textual as normas jurídicas de crivo tributário, onde nessas reparte para cada ente estatal suas competências tributárias específicas; e os princípios explanados do decorrer do texto constitucional que angariam, na maioria das vezes a repressão aos abusos do próprio Estado contra os direitos intrínsecos aos indivíduos. As garantias fundamentais deveriam assim, serem garantidas pelo próprio Estado devido esse ter sido legitimado pelo povo para tal função protetora. 
Nota-se assim que o sistema tributário nacional é posto pela Constituição a partir de normas princípios, que possuem função dúplice no ordenamento jurídico, pois ao mesmo tempo em que servem de fundamento da norma revestem-se também de caráter normativo, mas, modelável a cada caso concreto na busca do equilíbrio chamado de justiça. O entendimento de Roque Antônio Carraza (1995, p.29) acerca dos princípios jurídicos é que:

Princípio é um enunciado lógico, implícito ou explícito, que, por sua grande generalidade, ocupa posição de preeminência nos vastos quadrantes do Direito e, por isso mesmo, vincula, de modo inexorável, o entendimento e a aplicação das normas jurídicas que com ele se conectam.

$\mathrm{Na}$ ótica da busca pela aplicação da justiça tributária social, não é possível deixar de citar o Princípio da Igualdade, o qual dentro do complexo constitucional vigente possui valor supremo, pois dentro da interpretação de tal sistema em favor da sociedade sempre deve ter aquele princípio como supedâneo, pois, o mesmo materializa todos os tipos de liberdades dos indivíduos componentes do Estado social, integrado por tais instrumentos de efetivação das normas jurídicas.

Assim, a partir do que foi aqui exposto, é possível afirmar que o sistema tributário nacional, apesar de estar assentado em base principiológica, com evidente força normativa e fundamentabilidade, é genericamente considerado como sistema injusto, isso por duas questões centrais: o Estado arrecada muito, porém o índice de retorno ao cidadão é péssimo, ou seja, paga-se muito, por muito pouco; a tributação recai, de forma considerável, igualmente sobre o contribuinte, sem considerar os aspectos econômicos e financeiros relativos à capacidade de suportar tal tributação.

A Constituição vigente trás em seu bojo princípios e objetivos do Estado, devendo o interprete entender o caráter social dos mesmos. Como mencionado acima, os princípios possuem grande incidência no âmbito do sistema tributário nacional e são aplicados de diversas formas, desde a escolha governamental de determina política fiscal até a aplicação do produto fruto da arrecadação tributária, que deve ser balizada pelo dispositivo constitucional que trata dos objetivos fundamentais da República Federativa do Brasil.

Parece evidente ser plenamente possível falar em direitos humanos e tributação, porém não somente a visão liberal acerca dos direitos humanos, mas também a visão social dos mesmos, pautado na necessidade de respeito, por parte do Estado, de direitos inerentes à coletividade que está sujeita à tributação. Essa ideia de refutar a visão liberal dos direitos humanos é destacada por Enoque Feitosa (2013, p. 86), que destaca que a visão liberal- 
individualista dos direitos humanos limita as reivindicações à orbita das garantias individuais, excluindo a questão social. Ora, quando se fala em Direito Tributário e tributação, impossível afastar o fato de que os meios empregados na execução desse poder-dever do Estado acabam por afetar toda a coletividade, daí a necessidade de balizamento ético fundamental.

Nesse sentido, importante destacar a ideia de James Marins (2009, p.36), para quem “É um erro pensar que a tributação seja tema exclusivamente jurídico. A tributação é um tema econômico, político, sociológico, psicológico, ético. E, como ciência primeira, há a filosofia aplicada à tributação.

Assim, é imprescindível o reconhecimento de que a tributação possui laços estreitos com os direitos humanos.

\section{A QUESTÃo DA JUSTIÇA E OS REFLEXOS SOBRE A IDEIA DE JUSTIÇA TRIBUTÁRIA}

Entende-se por adequado analisar a ideia de justiça tributária a partir da obra de John Rawls, Uma teoria da justiça (2000). Rawls desenvolve ao longo da obra referenciada importantes bases para o entendimento de justiça, especialmente no que mais a frente será apresentada, que é justamente a questão tributária.

Rawls coloca como meta da justiça como equidade o fornecimento da base filosófica e moral aceitável para as instituições democráticas, entendendo a sociedade como sistema equitativo de cooperação social. A formulação desta ideia é feita em conjunção com duas outras: a ideia de cidadãos livres e a ideia de sociedade bem-ordenada, efetivamente regulada por concepção política de justiça. Segundo Rawls essa ideia de sociedade bem-ordenada especifica a ideia de sociedade como sistema equitativo de cooperação social.

Ao discorrer sobre a principal ideia da teoria da justiça, Rawls aduz que se trata de concepção de justiça como equidade e com leve teor do contratualismo do século XVII. Ele afirma no texto que o seu "objetivo é apresentar conceito de justiça que generalize e leve a nível mais alto de abstração a difundida teoria do contrato social, tal como se encontra formulado por Locke, Rousseau e Kant". Ele continua dizendo que "não se deve considerar o contrato original como contrato para entrar numa sociedade particular, ou para iniciar forma particular de governo". Ele diz que "melhor seria que a ideia principal fosse que os princípios de justiça para a estrutura básica da sociedade fossem o objeto do acordo original” (RAWLS, 2000, p. 33). 
Interessante ressaltar que Rawls desenvolve sua teoria a partir de dois princípios de justiça. Segundo Rawls o primeiro princípio revela que "cada pessoa deve ter a mais ampla liberdade, sendo que esta última deve ser igual à dos outros e a mais extensa possível, na medida em que seja compatível com liberdade similar de outros indivíduos. O segundo princípio consiste em que "as desigualdades econômicas e sociais devem ser combinadas de forma a que ambas correspondam a expectativa de que trarão vantagens para todos, e que sejam ligadas a posições e a órgãos abertos a todos" (RAWLS, 2000, p. 67).

Os princípios da liberdade e da diferença podem ser considerados assim a base da teoria da justiça de John Rawls, sendo que ambos possuem implicações evidentes quando da análise das questões de ordem tributária, porém há que se dar maior destaque neste momento ao segundo princípio, posto que a partir do mesmo é possível enfrentar a questão de como a tributação irá enfrentar o fato de que se vive numa sociedade extremamente desigual, onde as pessoas possuem capacidade econômica tão distintas etc.

Conforme observado por Eduardo de Abreu Moraes (2013), fica evidente que esses princípios que norteiam a obra de Rawls se referem mais aos efeitos dos institutos sociais do que às próprias características desses institutos e isso explicará mais a frente a talvez equivocada defesa feita pelo filósofo americano em relação aos tributos indiretos, essencialmente quando diante da sociedade com desigualdades sociais profundas como a brasileira. Assim, primordial quando se fala em justiça tributária é, revisitando a teoria de Rawls, que o sistema tributário não represente empecilhos demasiados à concretização de liberdades e que seja oportunidade de ganhos para as pessoas que estão socialmente em posição fragilizada e por isso não podem ser tributados da mesma fora que os social e economicamente mais favorecidos.

Essas ideias são fundamentais para que seja possível analisar o sistema tributário vigente no Brasil e verificar se o mesmo pode ser considerado sistema tributário justo, ainda que a Constituição Federal, como já mencionado, traga em seu texto normativo várias limitações do poder estatal, o que num primeiro momento revela ser algo decididamente protecionista em relação ao contribuinte.

A teoria de Rawls pode ser aplicável à analise que neste estudo se pretende fazer simplesmente pelo fato da mesma, através principalmente do princípio da diferença, defender a ideia de que as desigualdades sociais devem ser refletidas no âmbito da tributação, utilizandose assim evidente objetivo extrafiscal da tributação. Pouco importa para a o presente estudo se Rawls, ao tratar sobre a questão da justiça distributiva, defende a já mencionada tributação 
indireta, até pelo fato do autor não se dedicar profundamente à técnica tributária, especialmente em país como o Brasil, de tão profundas desigualdades.

Acerca da tributação indireta, aqui já foi mencionada anteriormente que a mesma é extremamente prejudicial à concretização, no Brasil, de valores como a capacidade contributiva, que em apertada síntese aponta para a tributação, sempre que possível, a partir da capacidade econômica do sujeito que está sendo submetido ao poder de tributar do Estado, ou seja, tributação que se coloque o mais próxima possível o sentido aristotélico de igualdade material. Assim, entende-se não ser possível a aplicação total das ideias de Rawls no que tange a tal modalidade de tributação.

Os impostos indiretos são cobrados ao consumidor final, que paga tributação excessiva, em efeito cascata, o que faz nascer a injustiça fiscal, pois o ônus que as famílias pagam desse imposto sobrepõe-se ao nível de sua renda. Consequentemente, esse fato alimenta a regressividade do nosso conjunto de arrecadação tributária.

A regressividade tem crescido no país, no decorrer de anos, pois essa faceta da tributação indireta, a qual incide sobre o consumo de bens e serviços, tem forte reflexo nos contribuintes de baixa renda, os quais estão pagando mais impostos do que os indivíduos que possuem renda mais considerável, sendo assim, esses ficam em posição de vantagem, pois, ganham mais e pagam menos quando comparado com o indivíduo que ganha um salário mínimo e paga a mesma quantia e tributos que aquele pagou, devido terem adquirido os mesmos produtos. Assim, nessa situação não houve tratamento desigual na medida da desigualdade para garantir a igualdade material da parte menos abastada.

$\mathrm{Na}$ medida em que a renda familiar aumenta os tributos diretos crescem, no entanto, não de forma proporcional para suportar a incidência direta no orçamento familiar, ou seja, há retração nessa proporção que deveria ser direta, o que explica o índice de regressividade do sistema tributário.

Destarte, para ser alcançada justiça fiscal tributária, a tributação deve ser prioritariamente direta e progressiva. Nessa medida, ela alcança a justiça social por meio de tratamento tributário equânime, proporcionando justiça distributiva com maior tributação sobre a renda do que sobre o consumo.

Conforme destacado, voltando a questão da extrafiscalidade tributária, a partir da concepção de justiça como equidade formulada por Rawls, tem-se que é instrumento preponderante para que seja concretizado nova visão do tributo, sendo este não somente instrumento de arrecadação, mas também, e principalmente, mecanismo pelo qual consegue o 
Estado induzir condutas, diminuir desigualdades sociais etc. Importante destacar que a extrafiscalidade trata-se de função dos tributos na qual estes fogem da simples função arrecadatória e passam para a concepção de exação tributária que possui significativa influência regulatória, social ou economicamente. Ora, não é possível enxergar o tributo somente como fonte arrecadatória.

Assim, diante do que foi exposto acima, é possível concluir que a justiça fiscal pode passar tranquilamente e beber da fonte do filósofo Jonh Rawls, fixando-se assim as bases para a definição de justiça como equidade na relação jurídica tributária, enxergando-se assim a tributação não como instrumento de expropriação nas mãos do Estado, mas sim instrumento capaz de diminuir as desigualdades sociais e regionais.

\section{O PAGAMENTO DO TRIBUTO A PARTIR DA NOÇÃO DE SOLIDARIEDADE}

A análise da tributação a partir da teoria da justiça de Rawls encaminha necessariamente para a concepção da justiça como equidade, aplicada à relação jurídica tributária, onde o contribuinte é chamado à, compulsoriamente, contribuir com a formação da receita pública estatal. O Estado, como organismo que realiza atividade financeira consistente em despesas e receitas públicas, necessita de recursos para sua própria manutenção, bem como para concretização dos objetivos postos no ordenamento jurídico.

Assim, não se pode conceber a tributação com outro objetivo senão a concretização dos objetivos fundamentais da República, diretamente expostos no artigo $3^{\circ}$ da Constituição Federal vigente (BRASIL, 1988), sendo exposto como um desses objetivos justamente a construção de sociedade livre, justa e solidária.

Mais do que simples instrumento de arrecadação, a tributação deve estar ligada a concretização de valores fundamentais do Estado, não se admitindo a visão meramente fiscal do mesmo. Enxergar a tributação ligada aos objetivos fundamentais expostos na Constituição deve ser entendido como decorrência do aprimoramento do próprio Estado, que não pode e não deve se furtar de colaborar para que as pessoas, físicas ou jurídicas, possam cumprir suas obrigações da maneira mais justa possível.

A efetivação dos objetivos fundamentais da República brasileira, especialmente a questão da sociedade solidária, passa obrigatoriamente pela análise crítica da forma de distribuição de que renda no país. A questão do aprimoramento da redistribuição da riqueza 
talvez seja das mais importantes e difíceis de serem enfrentadas, em que pese estarem sempre no foco das discussões, especialmente quando se discute o fenômeno da tributação.

Segundo Ricardo Lobo Torres (2005), o princípio da distribuição de rendas se refere justamente à forma como a tributação deve ser realizada a partir da capacidade do contribuinte. Citando Rawls, o mencionado autor afirma:

\begin{abstract}
John Rawls observa que o princípio da distribuição de rendas, subordinado ao ramo das finanças públicas que Musgrave chama de distributivo (distribution branch), atua mediante a tributação e os ajustes na propriedade; ao dispor sobre o imposto de heranças e ao estabelecer restrições ao direito de doar, não tem por objetivo coletar tributos para o governo, mas corrigir a distribuição de riquezas e prevenir as concentrações de poder que prejudiquem o 'justo valor da liberdade política e a igualdade de oportunidade’. (TORRES, 2005, p. 348)
\end{abstract}

Assim, vê-se claramente que a tributação pode instrumento de distribuição de riquezas, atendendo assim ao princípio da solidariedade, como objetivo fundamental do Estado. Destacando a solidariedade no ordenamento jurídico brasileiro, Fredys Orlando Sorto (2011, p. 115) afirma:

[...] Como categoría política y moral esa palavra pasó a tener también dignidade constitucional, por cuanto está contemplada em los llamados objetivos fundamentales de la República em la Constitución Federal de 1988. Nótese, de todas formas, que la noción se emplea con acerto como objetivo futuro, es decir, como proyecto de concreción del Estado a ser realizado mediante la construción de "una sociedad libre, justa y solidaria" (art. 3).

Pois bem, entende-se que o fenômeno da tributação está intimamente relacionado com o princípio da solidariedade, com destaque constitucional, conforme apontado acima. Não há que se falar em justiça fiscal tributária, nos moldes do que foi mencionado acima a partir da ideia de Rawls, sem a efetivação deste princípio e do consequentemente aprimoramento da distribuição de rendas e riquezas do país. Nesse ponto a tributação exerce papel preponderante.

A solidariedade age assim no campo da distribuição das riquezas, estando o Estado brasileiro compelido a atuar para que essa distribuição aconteça da forma mais eficiente possível. Ainda sobre o tema, é possível afirmar que no Estado fiscal encontra-se presente a ideia de compromisso do Estado com a questão da ideia redistributiva, como objetivo fundamental constituído (NABAIS, 2005, p. 129).

A base da discussão aqui tratada deve ser conectada com o constitucionalismo democrático, sendo importante destacar a ideia de Denninger que, em seu texto intitulado "Segurança, diversidade e solidariedade ao invés de liberdade, igualdade e fraternidade" (2003), lança um novo olhar na tríade clássica. Esse novo paradigma de Denninger tem 
encontrado respaldo inclusive na jurisprudência do Supremo Tribunal Federal, especialmente no que tange a discussão sobre o caráter solidário e contributivo de regimes de previdência, o que pode analogicamente ser inserido no contexto da tributação e consequentemente do Direito Tributário.

\section{A NECESSIDADE DE CONCRETIZAÇÃO DA CIDADANIA TRIBUTÁRIA COMO FORMA DE IMPLEMENTAÇÃO DOS DIREITOS HUMANOS A PARTIR DA PERSPECTIVA DE DIGNIDADE DA PESSOA HUMANA.}

A partir da ideia de justiça tributária, tal como tratado ao longo do presente estudo, surge a necessária concretização da cidadania tributária, o que também deve ser enfrentado a partir do abandono de ideias obsoletas e obscuras sobre o tema, conforme se sustentará adiante.

Para se falar em cidadania tributária é preciso de forma antecedente apontar algumas ideias básicas sobre o conceito de cidadania em modo geral, o que na maioria das vezes impõe, de forma equivocada, a utilização da cidadania grega como padrão a ser seguido e exemplo de participação política do povo. Conforme menciona Fredys Orlando Sorto (2011), a cidadania grega, em especial a de Atenas, não pode ser observada como modelo ideal de cidadania, pelo fato de que ali se verificava que a condição de cidadão era reservada a determinados grupos pertencentes a aristocracia ateniense, ficando a grande maioria à margem desse privilégio.

É preciso então tentar encontrar definições apropriadas para cidadania, o que pode ser feito através de Adela Cortina, para quem cidadania "é conjunto de direito e liberdades políticas sociais e econômicas, já estabelecidas ou não pela legislação" (2005, p.45). Impossível falar em cidadania sem mencionar a ideia de Hannah Arendt, que a considera como sendo a prerrogativa política do direito a ter direitos, criticando a concepção exclusivamente jurídica de cidadania como mera intitulação de direitos, indicando a necessidade de participação dos cidadãos na esfera pública.

A partir dessas ideias gerais sobre cidadania, necessário pensar agora sobre a mesma no âmbito do Direito Tributário do fenômeno da imposição tributária. A relação jurídica travada entre Estado e contribuinte, conflituosa e desigual desde a sua origem, representa uma relação de imposição estatal, sendo necessário que para a efetivação de justiça tributária haja a concretização da chamada cidadania tributária, passando esta pelos conceitos clássicos de cidadania acima expostos. 
A cidadania tributária passa necessariamente pela ideia de conscientização dos cidadãos acerca dos elementos estruturantes fundamentais que formam o sistema tributário nacional Tal sistema, complexo e extremamente confuso, é apresentado ao cidadão de maneira obscura, de modo que no Brasil paga-se muito tributo sem que haja a menor conscientização do porque e do para que paga-se ao Estado.

Como já mencionado, a relação travada entre Estado e contribuinte, o primeiro representado pelos órgãos fiscais de arrecadação e fiscalização, é extremamente conflituosa, muito em razão da falta de educação tributária e da equivocada mentalidade daqueles que representam o Estado. Os agentes públicos não possuem a consciência de que não são meros instrumentos de arrecadação e incorporam o espírito meramente fiscal, onde o objetivo é arrecadar a qualquer custo, ainda que a despeito da violação de normas fundamentais de proteção aos contribuintes. Os contribuintes, por sua vez, não são educados sobre questões fiscais, simplesmente desconhecendo elementos básicos de algo tão importante como a tributação. Neste cenário, não há que se falar em verificação de cidadania tributária.

Fato é que o sistema tributário nacional é tão injusto que o cidadão mais parece inimigo do Estado, ambos se colocando em lados diametralmente opostos, sem que haja a menos integração e colaboração. O Estado quer arrecadar a todo custo e o contribuinte resiste a essa pretensão de todas as formas, nem que para isso seja necessário sonegar tributos. Infelizmente essa é a realidade brasileira e a mesma aponta para quase nenhuma efetivação da noção de cidadania tributária.

A carga Tributária que é arrecadada no Brasil tem como alvo precípuo a satisfação econômica das necessidades básicas como saúde, educação, produção de emprego, ou seja, fornecer serviços públicos essenciais de qualidade para o cidadão-contribuinte. Sendo assim, a cobrança dos tributos tem como fundamento as ações do Estado como prestador de serviços, os quais viabilizam os cidadãos terem vida saudável, atendimento imediato a tratamentos de saúde, segurança, condições humanas de moradia, entre outras garantias fundamentais mínimas para efetivo bem estar social e, consequente início ao processo de efetivação do princípio da dignidade da pessoa humana, com base na universalização desses direitos.

Não é possível falar em cidadania tributária num país como o Brasil, onde se observa justamente a contra mão da materialização dos princípios constitucionais propostos pela Constituição Federal, vez que ainda é grande a regressividade no sistema tributário nacional, onde os pobres arcam com exações tributárias mais onerosas do que os ricos, o que gera sociedade injusta, preconceituosa e excludente. Além disso, existem diferenças exorbitantes nas 
parcelas de repasse financeiro dos tributos para os diferentes entes estatais causando maior desigualdade regional e atraso no desenvolvimento nacional.

O cidadão tem a obrigação de pagar imposto ("ability to pay") e evidencia-se nessa esteira que da mesma forma o Estado deve proporcionar ambiente de proteção para esses contribuintes, onde antes de serem indivíduos sobre os quais recai prestação pecuniária imposta por aquele, são seres humanos que possuem direitos humanos fundamentais.

É fácil perceber que da mesma forma que o cidadão deve contribuir para viabilizar financeiramente as prestações sociais do Estado, este último deve efetuar sua contrapartida junto à sociedade com o fito de cumprir sua obrigação precípua, ou seja, fornecer segurança e bem estar social aos indivíduos integrantes de seu espaço físico e político, sem intervir diretamente nas relações privadas desses cidadãos, mas sim viabilizar a dignidade em sua máxima plenitude. $\mathrm{O}$ dever do cidadão de pagar imposto reflete diretamente no atributo da cidadania tributária daquele, o qual deve ter consciência do ciclo de realização tributária que influencia diretamente em sua vida, independente de classe social.

Logo, cabe ao Estado criar medidas efetivas para que seja difundida de forma expansiva a educação direcionada à informação aos cidadãos-contribuintes no sentido de proporcionar aos mesmos o entendimento de como suas contribuições são utilizadas e, a importância dessas para o custeio dos serviços essenciais para estabelecimento de sociedade justa e igualitária, principalmente em relação ao acesso aos serviços essenciais, livre de qualquer sujeição à região em que estejam localizados ou de sua capacidade contributiva.

Em suma, efetivar-se-á justiça fiscal tributária e social no Brasil quando os órgãos estatais conseguirem arraigar a progressividade, suprimindo assim a regressividade avassaladora, cedendo lugar a sistema de exações proporcionais à capacidade contributiva dos contribuintes e rezando de forma integral os direitos sociais dos mesmos, os quais fundamentarão a vida social digna e com liberdade de transação para tais indivíduos angariarem efetivamente sua subsistência vital.

\section{CONSIDERAÇÕES FINAIS}

A partir de tudo quanto foi exposto ao longo deste trabalho, tem-se assentado o propósito da justiça fiscal. O complexo normativo tributário no âmbito nacional tem a exacerbação de sua base principiológica, porém é considerado sistema injusto, vez que o Estado arrecada muito, porém o índice de retorno ao cidadão é péssimo e, além disso, a grande parcela 
da tributação recai igualmente sobre o contribuinte, sem considerar os aspectos econômicos e financeiros relativos à capacidade de suportar tal tributação.

A alta carga tributária é grande fator negativo contrário à justiça fiscal tributária e promoção do desenvolvimento nacional, pois, o Estado arrecada bruta parcela pecuniária dos cidadãos-contribuintes com o objetivo se efetuar os serviços públicos essenciais da melhor forma possível para possibilitar àqueles terem vida digna, contudo, isso não tem ocorrido nessa sequência, onde o Estado não tem sido comprometido em realizar materialmente essa contrapartida com a sociedade; e sim tem angariado alta arrecadação abusiva; tem criado cada dia mais mecanismos de majoração dessa parcela pecuniária altíssima, sobrepondo, muitas vezes a tributação arrecadada em países desenvolvidos.

Passando pelas concepções de justiça como equidade, tal qual destacado na obra de Jonh Rawls, é preciso visualizar a tributação como mecanismo de distribuição de rendas, a partir do princípio da capacidade contributiva, contribuindo assim para a superação das desigualdades.

Falar em justiça como equidade no âmbito tributário é falar da aplicação do princípio da solidariedade no âmbito da relação jurídica tributária. Como mencionado, além de simples instrumento de arrecadação, a tributação deve estar ligada a concretização de valores fundamentais do Estado, não se admitindo visão meramente fiscal do mesmo. Ter os objetivos fundamentais expostos na Constituição como parâmetro de construção do sistema tributário mais justo é decorrência do aprimoramento do próprio Estado.

Como dito, a regressividade do sistema tem aumentado drasticamente, já que a tributação tem enfatizado à arrecadação dos tributos indiretos, que incidem sobre bens e serviços, os quais não refletem transparência das classes tributadas tratando assim todas de forma igual. O sistema tributário como posto funciona como mecanismo indutor de desigualdades, invertendo completamente a lógica do que foi assentado como justiça fiscal. Ao contrário do que defendeu Rawls, os tributos diretos devem ser veementemente prestigiados visto que, são propulsores a progressividade e justiça fiscal tributária.

Em decorrência da efetivação da ideia de justiça tributária, tal como aqui tratado, surge a necessária concretização da cidadania tributária. De fato, o cidadão tem a obrigação de pagar imposto ("ability to pay"), porém o Estado deve proporcionar ambiente de proteção para esses contribuintes, onde antes de serem indivíduos sobre os quais recai prestação pecuniária imposta por aquele, são seres humanos que possuem direitos humanos fundamentais.

Outro ponto que decorre também da concretização da ideia de justiça e cidadania 
tributária é o necessário acesso, por parte dos cidadãos contribuintes, às informações básicas sobre a tributação. É preciso fomentar o projeto de educação tributária e para tanto assumem papeis fundamentais o próprio Estado, mas também organismos que atuam em defesa da sociedade, tal como Ministério Público e Ordem dos Advogados do Brasil. Não há cidadania sem educação. Não há exercício de direitos, na acepção utilizada por Hannah Arendt, sem conhecimento desses direitos, daí a importância do que aqui é defendido.

Não se pode pensar a tributação de forma afastada da dignidade da pessoa humana, princípio fundamental da República Federativa do Brasil. Para que se possa entender dignidade da pessoa humana a partir do que aqui se defende, necessário enxerga-la de maneira distanciada das doutrinas amplas. Segundo Luis Roberto Barroso (2015), as características de um conteúdo mínimo para tal princípio “devem ser a laicidade - não pode ser uma visão judaica, católica ou muçulmana de dignidade -, a neutralidade política - isto é, que possa ser compartilhada por liberais, conservadores e socialistas - e a universalidade - isto é, que possa ser compartilhada por toda a família humana". Continua o autor mencionando que "os três elementos que integram o conteúdo mínimo da dignidade, na sistematização aqui proposta, são: valor intrínseco da pessoa humana, autonomia individual e valor comunitário".

Assim, não há que se falar em dignidade da pessoa humana sem que se possa verificar um sistema tributário com o mínimo de justiça fiscal, onde a tributação não seja um fim em si mesmo, visando apenas saciar a sanha arrecadatória do Estado, mesmo que para isso meios imorais sejam empreendidos. O valor comunitário acima destacado é fortemente enxergado quando se está diante do fenômeno da tributação.

No Brasil, falar em reforma tributária é caminho obrigatório para pensar em efetivação de justiça fiscal, desestabilizando assim, o ciclo das desigualdades em todos os entes da federação, e fornecendo redistribuição de renda, liberdade de transação, entre outras medidas já citadas, as quais convergem progressivamente para interações das garantias constitucionais.

É preciso entender e incorporar a concepção de que as exações não sejam formas de retirar os indivíduos a dignidade de sobrevivência, mas, sim sua finalidade precípua, ajudar ao Estado no sustento das suas obrigações para com os indivíduos componentes de seu elemento físico, buscando instrumentalizar as liberdades fundamentais dos indivíduos, distribuindo rendas e minimizando as desigualdades sociais e regionais. 


\section{REFERÊNCIAS}

BARROSO, Luis Roberto. O Constitucionalismo democrático no Brasil: crônica de um sucesso imprevisto. Disponível em: http://www.migalhas.com.br/dePeso/16,MI168919,51045-

$\mathrm{O}+$ constitucionalismo+democratico+no+Brasil+cronica+de+um+sucesso. Acesso em: 20 de outubro de 2019.

BONAVIDES, Paulo. Ciência Política. 13. ed., São Paulo: Malheiros, 2006.

CARRAZA, Roque Antônio. Curso de Direito Constitucional Tributário, 7. ed. São Paulo: Malheiros, 1995.

CORTINA, Aleda. Cidadãos do mundo, para uma teoria da cidadania. São Paulo: Loyola, 2005.

DENNINGER, Erhard. "Segurança, diversidade e solidariedade" ao invés de "liberdade, igualdade e fraternidade". Revista Brasileira de Estudos Políticos. N. 88. Belo Horizonte, 2003.

FEITOSA, Enoque. Bobbio e a crítica de Marx aos direitos humanos? Elementos para uma refutação da concepção individualista dos direitos humanos. In: TOSI, Giuseppe (org). Norberto Bobbio: democracia, direitos humanos, guerra e paz. João Pessoa: Editora da UFPB, 2013.

MARINS, James. Defesa e vulnerabilidade do contribuinte. São Paulo: Dialética, 2009. MORAES, Eduardo de Abreu. A tributação indireta sob a ótica da teoria da justiça de John Rawls. In: Sociedade Global e seus impactos sobre o estudo e a afetividade do Direito na contemporaneidade. Conpedi/Uninove. Disponível em: http://www.publicadireito.com.br/artigos/?cod=d99fa3a9dd5df426. Acesso em: 13 de ago. de 2015.

NABAIS, José Casalta. O dever fundamental de pagar impostos. Coimbra: Almedina, 2004

NOGUEIRA, Ruy Barbosa. Direito tributário: estudo de casos e problemas. São Paulo: Bushatsky, 1973.

PIOVESAN, Flávia. Direitos Humanos e o Direito Constitucional Internacional. 14. ed. Rio de Janeiro: Campus, 2013.

PORTELA, Paulo Henrique Gonçalves. Direito Internacional Público e Privado. 6. ed. Salvador: JusPODIVM, 2014.

RAMOS, André de Carvalho. Curso de Direitos Humanos. 1. ed. São Paulo: Saraiva, 2014.

SORTO, Fredys Orlando. La compleja noción de solidaridad como valor y como derecho. La conducta de Brasil em relación a ciertos Estados menos favorecidos. In: LOSANO, Mario G. 
(Ed.). Solidaridad y derechos humanos em tempos de crisis. Madrid: Dykinson, 2011. p 97-122.

SORTO, Fredys Orlando. O projeto jurídico de cidadania universal: reflexões à luz do direito de liberdade. Anuario hispano-luso-americano de derecho internacional, Madrid, vol. 20, p. 103-126, 2011.

TORRES, Ricardo Lobo. Tratado de Direito constitucional financeiro e tributário: valores e princípios constitucionais tributários. Vol. II. Rio de Janeiro: Renovar, 2005.

VILLEY, Michel. O direito e os direitos humanos. São Paulo: Martins Fontes, 2007.

Trabalho recebido em 27 de fevereiro de 2019

Aceito em 07 de julho de 2020 